\title{
FABRICATION OF HIGH-STRENGTH GRAY CAST IRON USING PERMANENT MAGNET SCRAP
}

\begin{abstract}
In this study, we have developed the manufacturing technology for high strength gray cast irons by using the spent permanent magnet scraps. The cast specimen inoculated by using a spent magnet scraps showed the excellent tensile strength up to $306 \mathrm{MPa}$. This tensile strength value is 50MPa higher than that of the specimen cast without inoculation, and is similar to that of the specimen inoculated by using the expensive misch-metal. These superior mechanical properties are attributed to complex sulfides created during solidification that promote the formation and growth of Type-A graphite. It is therefore concluded that spent magnets scrap can provide an efficient and cost-effective inoculation agent for the fabrication of high-performance gray cast iron.
\end{abstract}

Keywords: Gray cast iron, Rare earth element, Nd-Fe-B magnet scrap, Graphite formation, Microstructure

\section{Introduction}

Increasingly stringent environmental regulations worldwide have made the reduction of $\mathrm{CO}_{2}$ emissions and exhaust particulates a major issue for the automobile industry, prompting the development of core components that are light-weight or have highly specified features. These components have often been made from non-ferrous materials; however, they are generally more expensive than gray cast iron, and do not share its excellent castability, machinability and vibration damping characteristics [1-6]. This means that if gray cast iron components can be made thinner, then similar weight savings can be achieved as with nonferrous castings, but with superior performance [7,8].

Thinning gray cast iron components poses many technical problems, such as the fact that the increase in cooling speed in thinner castings tends to create a non-equilibrium chilled structure that, in turn, necessitates greater strength and fluidity. This can be suppressed by adding rare earth elements (RE) with a proper stoichiometric ratio into molten metal containing an appropriate amount of S and Mn [9-12], as the resulting complex sulfide acts as a core for graphite $[13,14]$. Unfortunately, the cost of most RE elements makes them commercially unsuitable for cast iron products.

Among the many permanent magnets in use today, those based on $\mathrm{RE}$ elements such as $\mathrm{Nd}$ and the byproducts of such magnets (including defective products or scraps generated during manufacturing) account for nearly $30 \%$ of all magnets produced. Spent magnets from small electronic devices, home appliances and automobiles that have reached the end of their useful life are also increasing annually. Although it is possible to extract the
RE elements from magnet byproducts and spent magnets, the recycling processes that have been developed are still far from being economically feasible [15-17]. This study therefore looks at whether using spent magnet strips in the inoculation process of cast iron can improve its strength while providing a new method of recycling spent RE-element-based permanent magnets.

\section{Experimental}

The reference cast iron composition used for this study (No. 1) was an alloy of Fe-3.3C-2.1Si-2.0Mn-0.1S (wt.\%), to which was added either misch metal (No. 2) or spent magnet strip (No. 3). The amount of misch metal (65Ce-35La, wt.\%) added was equivalent to $0.3 \mathrm{wt} \%$ of the entire molten metal, while the amount of spent magnet strip (33Nd-66Fe-1B, wt.\%) used was adjusted so that its $\mathrm{Nd}$ content became $0.3 \mathrm{wt} . \%$ of the entire molten metal. The chemical composition of each cast iron was measured by a spark emission spectrometer, the results of which are presented in Table 1.

TABLE 1

Chemical composition (wt.\%)

\begin{tabular}{|c|c|c|c|c|c|c|}
\hline \hline Specimen & C & Si & Mn & S & P & Remarks \\
\hline No. 1 & 3.25 & 2.11 & 1.96 & 0.1 & 0.1 & - \\
\hline No. 2 & 3.30 & 2.14 & 1.91 & 0.1 & 0.1 & RE addition \\
\hline No. 3 & 3.29 & 2.11 & 1.95 & 0.1 & 0.1 & Magnet strip addition \\
\hline
\end{tabular}

A $75 \mathrm{~kW}$ high-frequency induction furnace was used to melt $21 \mathrm{~kg}$ of pig iron and $6 \mathrm{~kg}$ of iron scrap to provide the

\footnotetext{
KOREA INSTITUTE OF RARE METALS, KOREA INSTITUTE OF INDUSTRIAL TECHNOLOGY, 12 GAETBEOL RD., YEONSU-GU, IN-CHEON, 21999, SOUTH KOREA 


\section{Results and discussion}

reference alloy, to which Fe-Si and Fe-Mn were then added to bring the total amount of molten metal to $28 \mathrm{~kg}$. The temperature of the melt was maintained at $1500-1530^{\circ} \mathrm{C}$, but momentarily increased to $1550^{\circ} \mathrm{C}$ prior to tapping at $1530^{\circ} \mathrm{C}$. The misch metal was wrapped in aluminum foil, placed into a ladle, and then inoculated after tapping. The waste magnet strip, on the other hand, was immediately inoculated after being put into the ladle, without any additional treatment after tapping.

After stirring the molten metal and removing any slag, it was poured at $1400^{\circ} \mathrm{C}$ into molds for a composition sample, a $\varphi 30$ rod-shaped tensile test sample for hardness and tensile testing, and a test sample for both total chill and clear chill depth. The latter molding was manufactured using the $\mathrm{CO}_{2}$ molding process to be in accordance with ASTM A367, and was laid on top of a 20-mm-thick copper plate prior to injecting with molten metal.

For an objective analysis of the fine structure of the cast iron types, the ends of each tensile test molding were cut to expose the middle-most part. The graphite was then observed using an optical microscope and classified in accordance with ASTM A 247. Observation of the graphite core was assisted by the use of field-emission scanning electron microscopy (FE-SEM), energy dispersive X-ray spectroscopy (EDS).

\subsection{Microstructure analysis}

Fig. 1a shows the fine structure of graphite in cast iron No. 1, in which both Type A and Type B graphite can be observed. The inoculation of misch metal in cast iron No. 2 produced mostly Type A graphite (Fig. 1b), with the RE elements in the waste magnet strip added to cast iron No. 3 producing solely Type A graphite. No significant difference was found in the shape or length of the graphite in cast iron No. 2 and No. 3, with both showing an increase in Type A graphite due to the addition of RE elements.

Fig. 2 shows the casting sample used to analyze the effect of RE element addition on the formation of a chilled structure, with the measured chill depths presented in Table 2. Fig. 2a shows that the total chill depth was equal to the length of the entire sample when no RE elements were added (cast iron No. 1), and that the clear chill depth was $20.7 \mathrm{~mm}$. With the addition of misch metal in cast iron No. 2 (Fig. 2b), the total chill depth was reduced to $8.9 \mathrm{~mm}$ and the clear chill depth to $7.5 \mathrm{~mm}$. Cast iron No. 3, on the other hand, had a total chill depth of $9.2 \mathrm{~mm}$
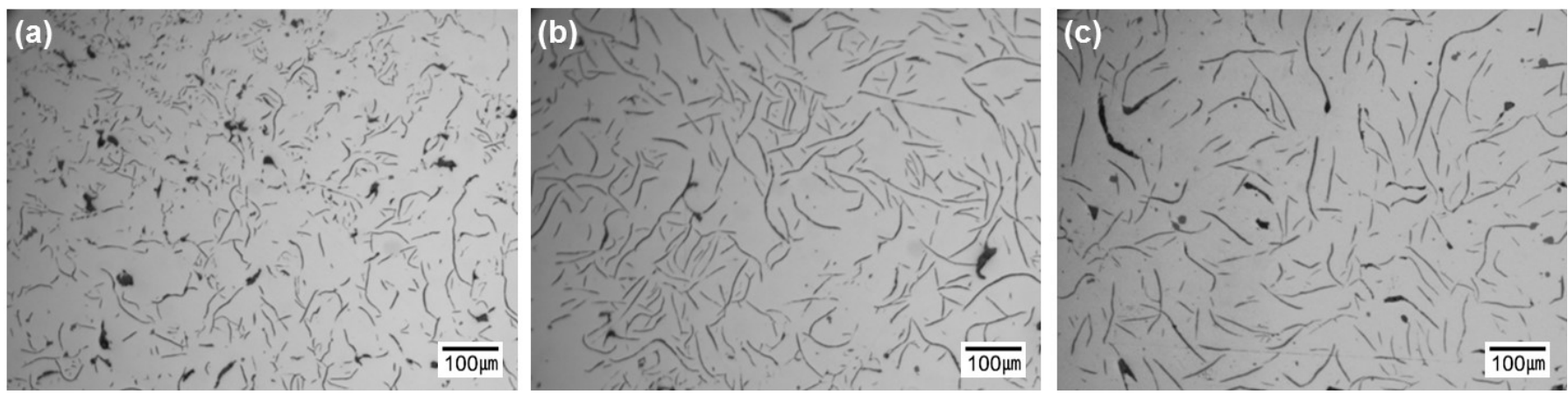

Fig. 1. Optical micrographs of graphite morphology in cast iron: (a) No. 1, (b) No. 2 and (c) No. 3
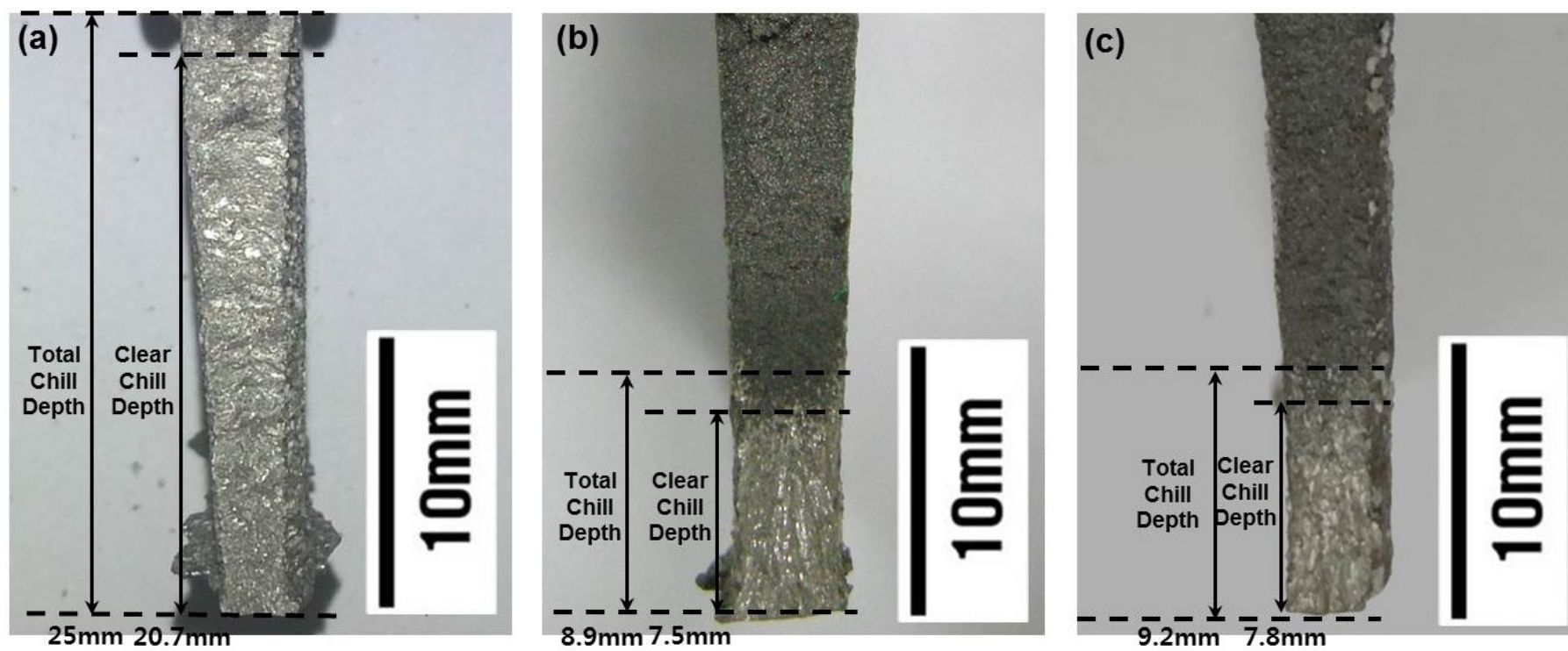

Fig. 2. Effect of RE element addition on chill depth: (a) No. 1, (b) No. 2 and (c) No. 3 
and a clear chill depth of $7.8 \mathrm{~mm}$ (Fig. 2c). The reason for the reduction of the chill depth is that the high Mn content of cast iron No. 1 promoted the formation of carbides, whereas the RE elements in cast iron No. 2 and No. 3 increased the amount of Type A graphite.

TABLE 2

Clear/total chill depth and tensile strength/hardness

\begin{tabular}{|c|c|c|c|c|}
\hline \hline \multirow{2}{*}{ Specimen } & \multicolumn{2}{|c|}{ Chill } & \multicolumn{2}{c|}{ Mechanical Properties } \\
\cline { 2 - 5 } & $\begin{array}{c}\text { Clear chill } \\
\text { depth (mm) }\end{array}$ & $\begin{array}{c}\text { Total chill } \\
\text { depth (mm) }\end{array}$ & $\begin{array}{c}\text { Tensile strength } \\
\text { (MPa) }\end{array}$ & $\begin{array}{c}\text { Hardness } \\
\text { (HB) }\end{array}$ \\
\hline No. 1 & 20.7 & Full & 252 & 243 \\
\hline No. 2 & 7.5 & 8.9 & 309 & 229 \\
\hline No. 3 & 7.8 & 9.2 & 306 & 234 \\
\hline
\end{tabular}

Although the addition of RE elements to cast iron can be effective in increasing the amount of Type A graphite and forming a graphite core, factors such as the casting used or the melting temperature and time can impede the formation of graphite. The amount of RE elements added is also a critical factor, as only a prescribed amount is needed to suppress the formation of a chilled structure through an increase in the graphite in the core. This is because RE element addition is highly affected by the $\mathrm{S}$ content of the iron, with a more pronounced increase in Type A graphite seen at S contents above $0.6 \mathrm{wt} . \%$. A RE:S ratio of between 2.5 to 5.0 is needed to promote the formation of Type A graphite, as at ratios below 2.5 both Type A and Type D graphite coexist [12]. Excessive RE element addition (i.e., a ratio of more than 5) promotes the formation of carbides, and is therefore detrimental to preventing the formation of a chilled structure [12]. This is consistent with the improved graphite formation in cast iron No. 2 and No. 3, both of which had a RE:S ratio of 3 (0.3 wt.\% RE element to 0.1 wt.\% S).

\subsection{Formation of graphite core}

The SEM images in Fig. 3 shows the fine structure of the graphite core. In Fig. 3a, a large amount of core material can be seen to have formed in the absence of any RE element addition, with few graphite flakes showing signs of growth. In contrast,
Fig. $3 \mathrm{~b}$ shows significant growth of graphite flakes around the core in the case of cast iron No. 2 due to the inoculation of misch metal.

Fig. $3 \mathrm{c}$ also shows much graphite flake growth around the core in the case of No. 3, in which waste magnet strip was inoculated, thus proving that RE element addition can be effective in increasing the amount of graphite core.

Chemical analysis found that the middle-most part of the graphite core in cast iron No. 2 (Fig. 4a) was MnS, but around this was an area of mostly $\mathrm{La}$ and $\mathrm{Ce}$. Graphite flake growth was also observed around these graphite cores. The graphite cores produced with waste magnet strip in Fig. $4 \mathrm{~b}$ also contained a $\mathrm{MnS}$ core, but with a surrounding layer of $\mathrm{Nd}$ rather than $\mathrm{La}$ and Ce. Nevertheless, graphite flake growth was still observed, indicating that misch metal and magnet strip are equally effective in promoting the formation of graphite flake cores. It is also evident from these results that the cores existed as a complex sulfide of Mn, S and RE elements, as opposed to a single phase.

Even when RE elements are not added, a considerable amount of $\mathrm{MnS}$ can be present, as shown in Fig. 3a. However, there is no growth of graphite stemming from these regions, as they have a NaCl-type crystal structure that is poorly matched to the hexagonal structure of graphite [18]. Any RE elements added to gray cast iron mostly form $\mathrm{RE}_{2} \mathrm{~S}_{3}$ prior to the formation of primary austenite [10]. At the eutectic temperature, this forms a complex sulfide of (RE,Mn) ${ }_{x} S_{y}$ that has a crystal structure well matched to graphite, thereby initiating the formation of a graphite core and the growth of graphite flakes [18]. The most effective RE element for forming a graphite core is known to be Ce, followed by La, Nd and Y [19]. As shown in Fig. 4b, the formation of graphite cores by adding $\mathrm{Nd}$ as spent magnet strip creates a complex sulfide of $(\mathrm{Nd}, \mathrm{Mn})_{\mathrm{x}} \mathrm{S}_{\mathrm{y}}$ centered around a $\mathrm{MnS}$ core. This promotes the formation of Type A graphite and helps prevent a chilled structure.

\subsection{Mechanical properties}

The most representative mechanical properties of gray cast iron (i.e., the tensile strength and hardness) were measured to determine any change between the different experimental compo-
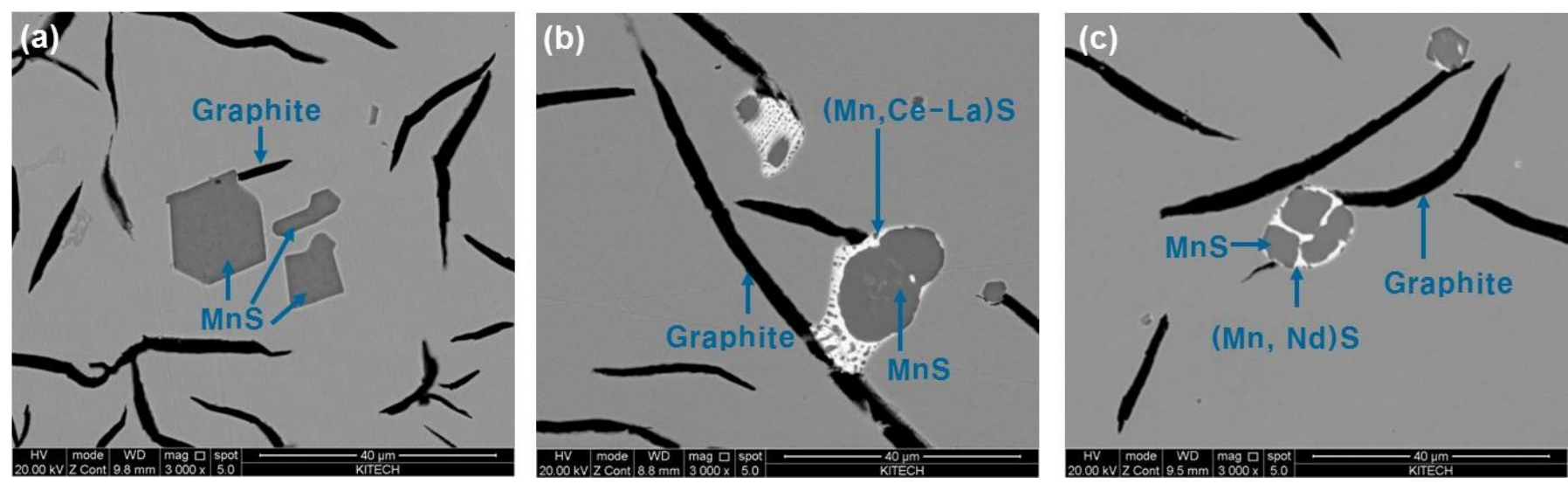

Fig. 3. Effect of RE element addition on nucleation behavior of graphite: (a) No. 1, (b) No. 2 and (c) No. 3 

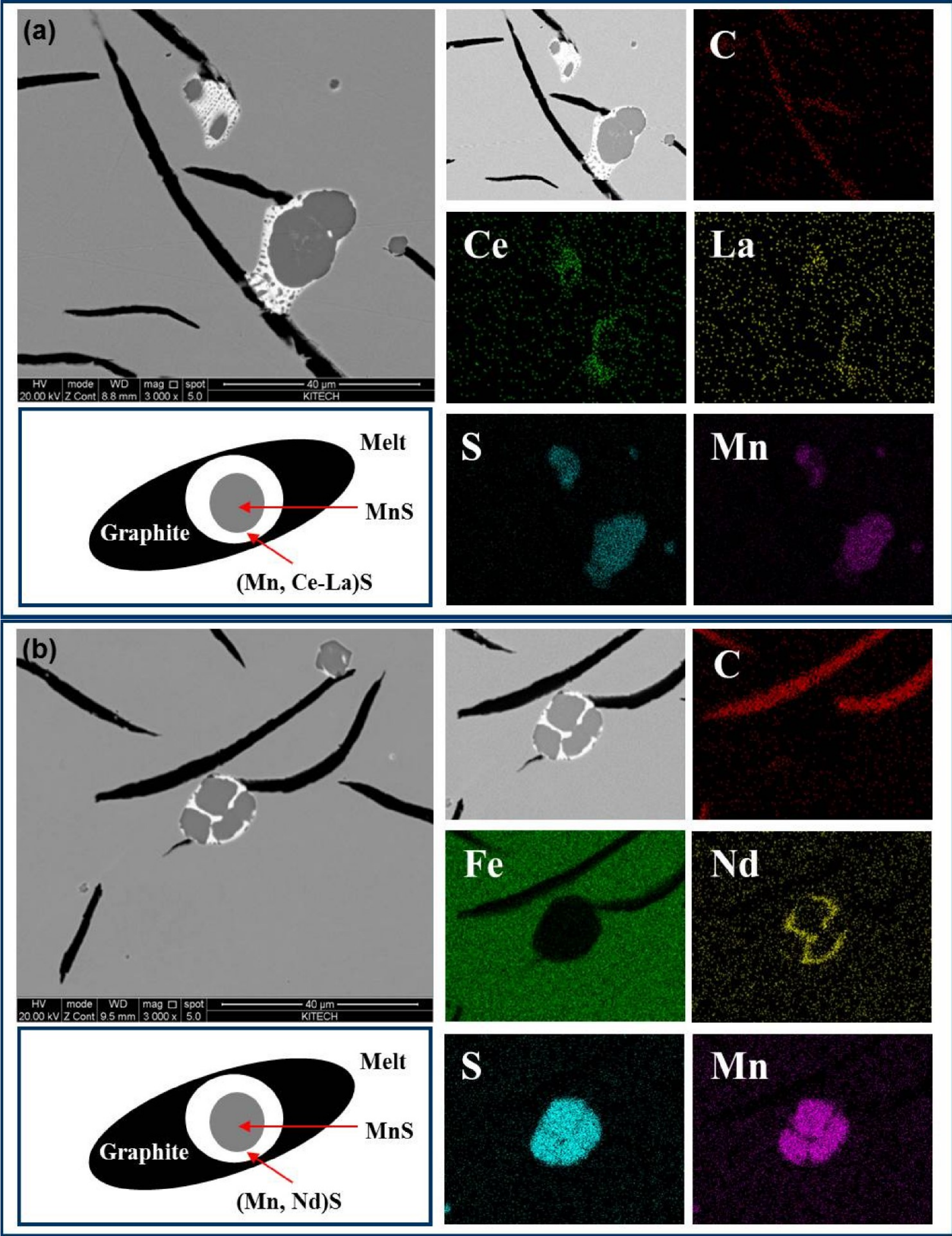

Fig. 4. EDX-maps of graphite nucleation: (a) No. 2, (b) No. 3 
sitions, as shown in Fig. 5 and Table 2. Note that both the tensile strength and Brinell hardness represent an average of 3 measurements. We see from this that the tensile strength increased from 252 to $309 \mathrm{MPa}$ with the addition of misch metal and to $306 \mathrm{MPa}$ with the addition of the spent magnet strip, while the hardness decreased from 243 to 229 and $234 \mathrm{HB}$, respectively. This de- crease in hardness can be attributed to the suppression of a chilled structure by the (RE,Mn) $)_{\mathrm{x}} \mathrm{S}_{\mathrm{y}}$ complex sulfide and graphite core, with the resulting increase in Type A graphite accounting for the increase in strength. More importantly, the addition of Nd using spent magnet strip achieved comparable mechanical properties to the addition of Ce and La using misch metal.
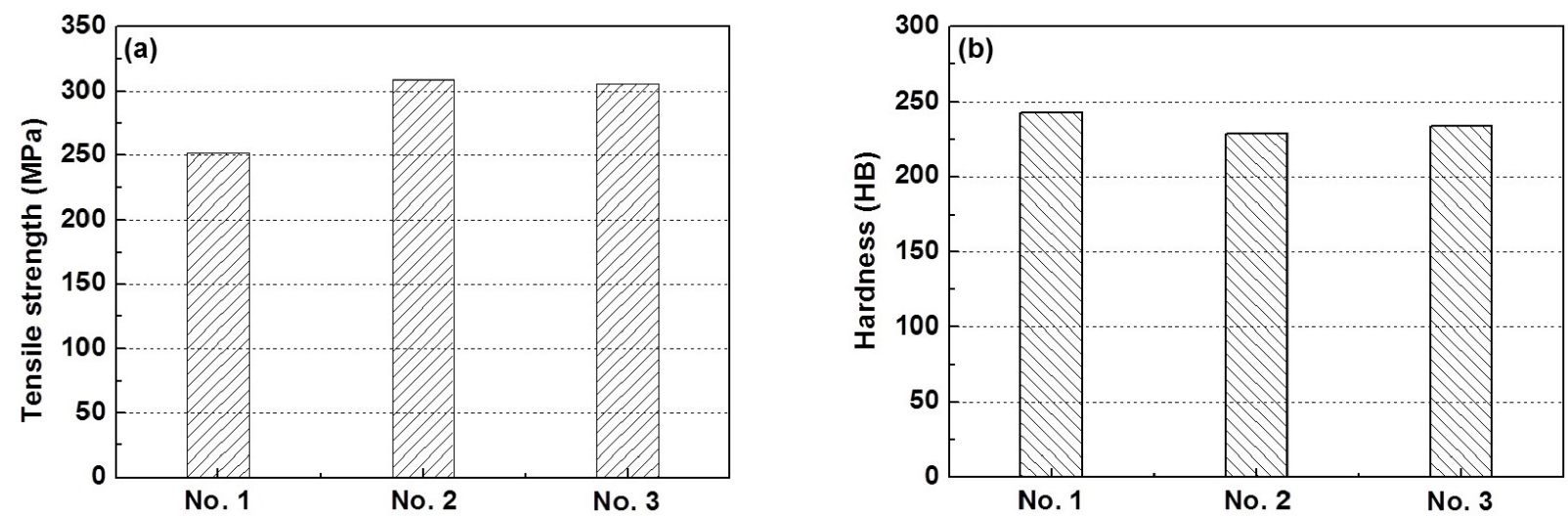

Fig. 5. Effect of RE element addition on (a) tensile strength and (b) hardness

\section{Conclusions}

In this study into whether spent magnet strip can provide an RE element source for high-strength cast iron that is as effective as misch metal, the following conclusions have been reached.

1) The addition of misch metal (No. 2) and spent magnet strip (No. 3) both increase the amount of Type A graphite and reduce the chill depth when compared to the base metal (No. 1). This addition of RE elements increases the strength of the metal and reduces its hardness.

2) No major difference in chill depth, strength or hardness was found between adding misch metal or spent magnet strip. The shape of the graphite formed in each case was also similar.

3) The addition of Nd using spent magnet strip produces a complex sulfide with the form $(\mathrm{Nd}, \mathrm{Mn})_{\mathrm{x}} \mathrm{S}_{\mathrm{y}}$, which is effective in promoting the formation of graphite and enhancing the mechanical characteristics of the metal.

4) Inoculating RE-element-based permanent magnet byproducts instead of more costly RE element sources like misch metal can provide an effective approach to manufacturing high-quality gray cast iron.

\section{Acknowledgments}

This work has been supported by the Ministry of Strategy and Finance(MOSF). The authors would like to thank the MOSF for its financial support.
[1] E.A. Loria, Iron Age 172, 158-161 (1953).

[2] J.F. Janowak, R.B. Gundlach, AFS Trans. 93, 961-968 (1985).

[3] P. Millet, R. Schaller, W. Benoit, J. Phys. Colloques. 46, 405-408 (1985).

[4] C.F. Bates, Mod. Cast. 86, 36-39 (1996).

[5] R. O'Rourke, M. Grander, Gear Tech. 16, 46-49 (1999).

[6] T. Murakami, T. Inoue, H. Shimura, M. Nakano, S. Sasaki, Mater. Sci. Eng. A. 432, 113-119 (2006).

[7] L. Collini, G. Nicoletto, R. Konečná, Mater. Sci. Eng. A. 488, 529-539 (2008).

[8] H. Nakae, K. Fujimoto, Key Eng. Mater. 457, 25-30 (2011).

[9] E. Fritsche, Giesserei-Rundschau 56, 160-164 (2009).

[10] T. Kowata, H. Horie, S. Hiratsuka, E. Sato, J. Jpn. Foundry Eng. Soc. 68, 856-869 (1996).

[11] T. Kanno, I. Kang, T. Mizuki, H. Nakae, J. Jpn. Foundry Eng. Soc. 73, 441-446 (2001).

[12] S.H. Lee, S. Hiratsuka, H. Horie, T. Kowata, C.O. Choi, J. Jpn. Foundry Eng. Soc. 74, 285-290 (2002).

[13] I. Riposan, M. Chisamera, S. Stan, T. Skaland, Int. J. Cast Metal Res. 16, 105-111 (2003).

[14] I. Riposan, M. Chisamera, S. Stan, T. Skaland, M.I. Onsoien, AFS Transactions 109, 1151-1162 (2001).

[15] F. Michihiko, M. Bunkichi, A. Iktsuaki, Kokai Tokkyo Koho Jp. 63128216 (1987).

[16] J.W. Lyman, G.R. Palmer, Recycling of Neodymium Iron Boron Magnet Scrap, U.S. Bureau of Mines, 1993.

[17] J.W. Lyman, G.R. Palmer, J. Met. 45, 32-35 (1993).

[18] T. Kanno, T. Mizuki, H. Nakae, J. Jpn. Foundry Eng. Soc. 74, 305-311 (2002).

[19] H. Horie, Z. Yang, T. Kowata, S. Hiratsuka, X. Yuan, Y. Shobuzawa, J. Jpn. Foundry Eng. Soc. 68, 143-148 (1991). 